\title{
The Burden of Motherhood: An Assessment of Government Policy Towards Exclusive Breastfeeding Among Working Mothers in Nigeria
}

La carga de la maternidad: Una evaluación de la política gubernamental hacia la lactancia materna exclusiva entre las madres trabajadoras en Nigeria

Linda Nwaodu

University of Edinburgh - United Kingdom

Edinburgh, United Kingdom

l.u.nwaodu@sms.ed.ac.uk

\section{Abstract}

Nigeria has witnessed a rapid increase in female labour participation such that it risks a decline in exclusive breastfeeding (EBF) rate - despite the World Health Organization's and government's endorsement of EBF. EBF is a beneficial process of feeding an infant with breast milk only during the first six months. This study aims to assess the extent to which the Nigerian policy addresses the barriers and contribute to improved EBF rates among working mothers in Nigeria. It takes a qualitative approach - policy analysis. The policy analysis critically evaluated the content of the National Policy on Infant and Young Child Feeding in Nigeria (2010) and the Labour Act (2004). The policy documents addressed these barriers to an extent. However, they showed minimal coherence. There are still policy gaps and disparity between the policies and their implementation - attributable to inadequate clarity and insufficient mechanism to spur policy compliance. Therefore, nutritionists should be engaged in such nutrition-specific policy formulation. Further research to measure the impact of this recommendation is encouraged.

Keywords: Exclusive breastfeeding, working mothers, maternal work, Nigerian policy, breastfeeding policy.

\section{Resumen}

Nigeria ha sido testigo de un rápido aumento de la participación laboral de las mujeres, de tal manera que se corre el riesgo de que disminuya la tasa de lactancia materna exclusiva (LME), a pesar de que la Organización Mundial de la Salud y el gobierno respaldan la LME. La LME es un proceso beneficioso que consiste en alimentar al bebé con leche materna sólo durante los primeros seis meses. Este estudio pretende evaluar en qué medida la política nigeriana aborda los obstáculos y contribuye a mejorar las tasas de LME entre las madres trabajadoras de Nigeria. Adopta un enfoque cualitativo: el análisis de políticas. El análisis de políticas evaluó de forma crítica el contenido de la Política Nacional sobre Alimentación de Lactantes y Niños Pequeños en Nigeria (2010) y la Ley del Trabajo (2004). Los documentos políticos abordaron estos obstáculos en cierta medida. Sin embargo, mostraron una coherencia mínima. Todavía existen lagunas políticas y disparidades entre las políticas y su aplicación, atribuibles a una claridad inadecuada y a un mecanismo insuficiente para estimular el cumplimiento de las políticas. Por lo tanto, los nutricionistas deberían participar en la formulación de estas políticas específicas de nutrición. Se alienta la realización de nuevas investigaciones para medir el impacto de esta recomendación.

Palabras clave: Lactancia materna exclusiva, madres trabajadoras, trabajo materno, política nigeriana, política de lactancia materna. 


\section{Introduction}

Following the Innocenti Declaration in August 1990, Nigeria has actively promoted breastfeeding practices such that it was among the 12 countries selected to pioneer the Baby-Friendly Hospital Initiative (BFHI) in 1991 (Worugji \& Etuk, 2005). The Innocenti Declaration was a meeting tagged "Breastfeeding in the 1990s: A Global Initiative" led by the World Health Organization (WHO) and United Nations Children's Fund (UNICEF) policymakers to acknowledge and promote breastfeeding policies which resulted in BFHI. As a result, Nigeria formulated the National Breastfeeding Policy (Worugji \& Etuk, 2005) which later became the National Policy on Infant and Young Child Feeding in Nigeria (2010) (FMoH, 2010). Like many countries, Nigeria also celebrates the World Breastfeeding Week every August in solidarity for breastfeeding promotion (IBFAN, 2017).

Despite this annual celebration, and efforts of the BFHI and National Policy on Infant and Young Child Feeding in Nigeria (2010) to encourage exclusive breastfeeding (EBF) among nursing mothers in Nigeria, EBF rate in Nigeria has remained low (NBS \& UNICEF, 2018). This indicates a gap in the Nigerian policy or a disparity between policy formulation and implementation or even both (Worugji \& Etuk, 2005). This is attributable to lack of clearly defined policy context, an insufficient mechanism to spur policy compliance, inadequate funding and human capital to promote implementation, and redundant research (Obamwonyi \& Aibieyi, 2014). Therefore, if the Nigerian government must continue to advocate and support EBF, there is a need to ensure that these policies are evidence-based, well-targeted and implemented.

In 2015, Nigeria's female labour participation increased by $48.3 \%$ such that the percentage of employed women in the non-agricultural sector rose to $41 \%$ (Akinyemi, et al., 2018). By 2019, female participation in both the formal and informal markets was reported to be on a positive trajectory in both rural and urban Nigeria (Institute, Evidence and Learning for Development, 2019). In the view of Fapohunda (2012), this arose from the decline in local and national economies which has made the provision of households needs become increasingly challenging for men. The implication of this is an increased household pressure on women. However, Fapohunda (2012) argues that unlike men, women are better household incomes managers who invest their incomes into their homes. This translates into a better quality of life for their families.

Effectively, these women combine work and domestic responsibilities to be financially empowered and bridge the gender gap in the labour market simultaneously (Institute, Evidence and Learning for Development, 2019). As these women of childbearing age opt for informal work or formal employment, their return-to-work post-partum poses a threat to the Nigerian government's effort to promote EBF (Tsai, 2013). Therefore, the country risks a decline in its EBF rate. This is because EBF is demanding despite its numerous benefits (Ogbo et al., 2015).

\section{Method of Policy Analysis}

Social policies are policies formulated to enhance the well-being and welfare of the people (Midgley \& Livermore, 2009:x). They are designed to address the needs of a population group such as children, women and low-income families. These needs could be income, education or even nutrition - which is the focus of this study.

This study targeted social policies addressing infant nutrition and maternal employment. This resulted in the inclusion of two national policy documents based on their relevance in addressing the barriers to EBF among working mothers in Nigeria. Only policy documents addressing the needs of women and children particularly in the areas of Infant and Young Child Feeding (IYCF) and maternal work were included in this study. The included policy documents were published in English and formulated by the Federal Republic of Nigeria. To ensure up-to-date evidence, only the revised versions of the policy documents were included. Policy documents that did not meet these criteria were eliminated.

Based on the above criteria and previous study by Worugji \& Etuk (2005), two national policy documents were included for analysis. These documents are 'The National Policy on Infant and Young Child Feeding in Nigeria (2010)' and the 'Labour Act (2004)' sourced from the Federal Ministry of Health and International Labour Organization (Nigeria chapter) websites respectively.

Although Worugji \& Etuk (2005) conducted similar research in Nigeria and utilized both policy documents, these policy documents were unrevised at the time. Therefore, their research evidence is outdated and unlikely to be relevant in informing the current national policy to support working mothers in Nigeria. 


\subsection{Overview of the Policy Documents}

The National Policy on Infant and Young Child Feeding in Nigeria (2010) is a comprehensive document which aims to promote optimal growth, development and protection of the Nigerian child aged o-5 years (FMoH, 2010, p. 4). It was revised in November 2010 and released by the Department of Family Health, Federal Ministry of Health Nigeria. Before its revision, it was known as the National Breastfeeding Policy (1990) (Worugji \& Etuk, 2005). Asides from infants, under-five children and mothers, the revised policy document authored by Nigeria's Honourable Minister of Health (Professor C. O. Onyebuchi) (FMoH, 2010, p. vii) and other health policymakers identifies health workers, caregivers, research institutions, policymakers, regulatory agencies, all levels of governments and media organizations as key stakeholders necessary to fulfil its aim (FMoH, 2010, pp. i-ii).

On the other hand, the Nigeria Labour Act (2004) was first adopted in 1971 and later published in 1974 (ILO, 2014). The Act which constitutes a chapter in the Laws of the Federal Republic of Nigeria was later revised in 2004 to provide detailed legislation on work conditions and employment such as maternal workplace entitlement. Hence, it summarizes employer and employee relations. Effectively, both policy documents are relevant in addressing the many barriers to EBF among working mothers. The a-priori expectation of the analysis later in this paper is that the two national policies targeted at nursing mothers are robust.

\subsection{Content Analysis}

Content analysis - a research technique for making valid and replicable inferences from texts - was used to analyse the policy documents while considering the purpose, discourse or context of the documents. It is widely used in health studies and social science research and helps researchers reflect on the data content thereby producing an in-depth analysis. Due to the qualitative nature of the overall study, a qualitative content analysis was employed to systematically transform each policy document into an organised and concise summary of key results. The result was then reported narratively to provide robust information on framing the problem, policy and action of each document.

The analysis addressed the issues and stakeholders relevant to each policy document. Additionally, for "each policy document, the analysis focused on what actions were discussed, those responsible for the outlined actions and when the outlined actions are to be implemented" (Krippendorff, 2004, p. 24).

\section{The Nigerian Policy on EBF}

This paper aims to address the extent to which the Nigerian policy addresses the barriers to EBF among working mothers in Nigeria. To achieve this, it will focus on the description of the policy documents using content analysis while the subsequent section will critically appraisal the policy documents - which are the National Policy on Infant and Young Child Feeding in Nigeria (2010) and the Labour Act (2004) formulated by the Federal Republic of Nigeria.

\subsection{The National Policy on Infant and Young Child Feeding in Nigeria (2010)}

This aims at promoting the growth and development of children under-five years (FMoH, 2010: i-ii). While infant and young child is a proximal role of the mother, collective effort is required to ensure an optimal result. Hence, it uses the term "caregivers to describe individuals other than the mother or health workers" $(\mathrm{FMoH}, 2010$, p. 8). Additionally, it encourages the education of relatives and other relevant persons on "the benefits of breastfeeding over bottle-feeding" (FMoH, 2010, p. 8). However, the directive does not discuss the roles of these relatives in promoting EBF extensively.

The policy recognizes IYCF as a child's fundamental right such that the Honourable Minister of Health, Professor C. O. Onyebuchi refers to the Convention on the Rights of the Child (Article 24) in its preface (FMoH, 2010, p. vi). Furthermore, it promotes EBF followed by adequate complementary feeding up to the first 24 months of the child's life in compliance with the WHO's Global Strategy for Infant and Young Child Feeding.

The directive emphasizes that the critical window of opportunity from birth to 2 years plays a significant role in a child's health and well-being. Hence, it promotes EBF and complementary feeding (FMoH, 2010, p. vi). However, it acknowledges that the high prevalence of HIV infection among pregnant women in Nigeria may potentially threaten EBF practice (FMoH, 2010, p. 1). Effectively, this was the rationale for the policy revision. To ensure that the health of children birthed by HIV-infected mothers is not compromised, 
the directive encourages HIV-infected nursing mothers on anti-Retroviral (ARV) treatment to breastfeed (FMoH, 2010, p. vi). However, the directive urges health workers to respect the decision of HIV-infected mothers who refuse to breastfeed but advises the health workers to provide the mothers with adequate information and support to ensure optimal nutrition for the child.

The policy is also conscious of Nigeria's triple burden of malnutrition (FMoH, 2010, p. 2) and is keen on addressing them through its objectives $(\mathrm{FMoH}, 2010, \mathrm{p}$. 4). These objectives include enhancing the provision of enabling environment void of discrimination, providing adequate nutrition information and empowering women including those working outside their homes (FMoH, 2010, p. 4). Unfortunately, this is the only instance where working mothers are acknowledged by the directive -- despite the many barriers to EBF confronting working mothers.

The government highlights special situations where infants and young children may require additional support in the following order: infants of HIV-infected mothers, sick infants, infants with low birth weight (LBW), motherless/adopted infants, infants and young children in emergencies, infants of adolescent mothers and infants with cleft palate. Given that the rationale "behind the policy revision was to account for infants of HIV-positive mothers" (FMoH, 2010, p. 3) clearly explains their consideration as a special situation. However, the government did not account for infants birthed through caesarean section who may be confronted with poor maternal lactation. Also, "the directive does not account for infants of working mothers as a special situation despite the many barriers to EBF faced by these working mothers" (FMoH, 2010, p. 19). Although, it promotes the establishment and strengthening of community-based breastfeeding support groups which is beneficial to both the working mothers and their infant.

The government outlines nine strategies to help achieve the goals and objectives of the policy. There are legal, gender and cultural considerations, advocacy and social mobilisation, counselling and support services, capacity building and development, research, monitoring and evaluation, supervision, coordination, and Communication for Behaviour and Social Change (CBSC) (FMoH, 2010). Specifically, the legal, gender and cultural considerations address gender equality, equity and maternity entitlement (FMoH, 2010). However, the issues relevant to working mothers were not explicitly discussed - attributable to the policy's constant reference to other national documents such as the Labour Act (2004) expected to explore the issues in detail (FMoH, 2010).

As part of the policy, both formal and informal IYCF training to promote EBF are encouraged especially among the health workers $(\mathrm{FMoH}, 2 \mathrm{2010})$. Similarly, the policy promotes nutrition counselling offered by health workers and relevant organizations $(\mathrm{FMoH}, 2010)$. The research aimed at improving IYCF is highly encouraged by the government, although no stakeholder was specifically appointed to execute this task (FMoH, 2010). Conversely, the government outlines monitoring and evaluation, supervision and coordination as strategies to ensure transparency, accountability and interventions modification if necessary - and appoints the Nutrition Division of the Federal Ministry of Health for its execution (FMoH, 2010).

Effectively, the policy makes an ambitious attempt to achieve its goals and objectives to promote IYCF by clearly outlining the role of various stakeholders. However, it omitted spouses' and employers' role(s) in IYCF (FMoH, 2010). Perhaps, this is due to Nigeria's patriarchal nature that bestows domestic roles on women and limits them from pursuing a career (The Guardian, 2018). Also, it explores in detail other child survival strategies (such as immunization, growth monitoring, vitamin and mineral supplementation, and oral rehydration therapy) as opposed to IYCF (FMoH, 2010). Thereby, undermining the relevance of the EBF among infants of working mothers.

\subsection{Labour Act (2004)}

The Act is divided into four parts which are further divided into sections (ILO, 2012). The first part outlines the general terms of employment and protection of wages while the second part regulates recruiting such as licensing of recruiters (ILO, 2012). On the other hand, the third part protects special classes of workers - including working mothers - while the last part outlines supplemental information relating to dispute settlement and administration. This suggests that of the four parts of the Labour Act, only the third acknowledges the needs of working mothers. The Act recognizes the minister, employers, employees, state authorities and employees' families as stakeholders (ILO, 2012). 
The part I section 7(1) clearly states that the deeds of agreement (including the hours of work) between the employer and employee be outlined in a written document. This is further discussed in detail in section 13(1). This directive aims to avoid unnecessary dispute between both parties. It allows the employee particularly the working mother to be conscious of her working hours and any other benefits accrued to her office. Although finance, is not a known barrier to EBF among working mothers, section 4(4) states that employers do not reserve the right to make any deduction in an employee's wages unless an advance has been previously paid to the worker as stated in section 4(5). This suggests that employees have no right to reduce or deny working mothers of their maternity allowance. Additionally, the directive makes provision for informal employment -by acknowledging agricultural work in subsection 8(2)(i).

Part II of the directive explores recruitment such as licensing of a recruiter and employment provisions. Sections 34 and 44 outline states that recruiters shall allow family members to accompany employees to their place of employment. This suggests that families of employees are allowed to move into the cities where the employee is working. However, in the case of national employment, section 34 states that employees must cater for their families. However, for international employment, section 44 states that the employer must provide facilities to enable the employee's family to accompany them and remain until the contract ends. This suggests to an extent that the directive understands the importance of family especially when the family member is under sixteen years of age as referenced in section 34(1).

Also, section 46(1) states that employers who ill-treat or neglect their employee will be sanctioned and liable to a fine of not more than NGN 500 or imprisonment for a period not more than a year, or both. This suggests that the directive is aimed at protecting the rights of the employees. The directive constantly refers to all employees as males - which may have informed the directives omission of breastfeeding spaces and facilities in this part. However, sections 54-58 in Part III of the directive specifically account for women in employment.

Part III discusses women in employment. The section 54(1) of the directive permits a woman to be absent from work 6 weeks to her confinement and authorizes the recruiter to oblige her to be absent 6 weeks to her confinement following a medical report. The term 'confinement' in this case refers to 'labour' or childbirth. Subsection 54(1)(c) states that a woman in this condition must have been employed for 6 months or more to be entitled to at least $50 \%$ of her wages during the confinement. Also, subsection $54(1)(d)$ states that nursing employees are entitled to 30 minutes of breaks twice daily. This implies that employed mothers in Nigeria are entitled to maternity leave with at least half pay and two breastfeeding breaks upon resumption. However, subsection 54(2)(b) reveals that a woman is not entitled to any job security if they exceed the prescribed maternity leave. Although, employers are not permitted to dismiss her in absentia but reserve the right to do so following her resumption (ILO, 2012).

Regarding working hours, section 55(1) exempts women in any establishment from night work - however, nurses and women in managerial positions, private organizations or in any agricultural establishment whose work do not require manual labour are permitted to work on the night shift as stated section 55(2) especially if raw material subject to deterioration are involved. Subsection 55(3)(a) clearly states that the term 'night' includes the period between $10 \mathrm{pm}$ and $5 \mathrm{am}$. This section is ambiguous and somewhat permits nearly all category of women to work on the night shift.

The directive considers the type of work done by women in Section 56 . However, while women are exempted from underground work in section 56(1), section (2) permits an array of women to perform underground work including those employed in welfare and health services, those in which underground work is necessary to fulfil their study and those in managerial positions that do not require manual labour. This largely contradicts the directive given in section 56 . Following this, the government states that an employer who violates section 54 is liable to a fine of not more than NGN 200 or imprisonment of not more than three months or both. Similarly, an employer who violates section 55(1) or 56(1) is liable to a fine of not more than NGN 100 or imprisonment of not more than one month or both. Also, the directive makes provisions to protect the rights of both the employers and employees through the settlement of the dispute which it outlines in section 80-84.

The directive gives limited consideration to working mothers, and where it attempted to do so in part III, the directives are either insufficient or unclear to ensure maximum protection for the working mothers and the breastfed child - to improve Nigeria's EBF rates. 


\section{To what extent does the Nigerian Policy address the evidence?}

For this paper, the barriers to EBF among working mothers in Nigeria is classified into maternal, social and work-related factors (Gebrekidan et al., 2020). This section will discuss the extent to which the Nigerian policy addresses these barriers and issues useful in explaining the Nigerian policy. Effectively, this will begin with a work-related factor which is the major barrier to EBF among working mothers in Nigeria.

\subsection{Work-related factors}

Several studies have shown that work is a major barrier to EBF practice among working mothers (Nkrumah, 2016; Chekol, et al., 2017; Tadesse et al., 2019). Effectively, the evidence showed that poor workplace structure - including short maternity leave, inadequate breastfeeding breaks, huge workloads, and inadequate breastfeeding spaces - are a major hindrance to the practice of EBF among working mothers. In Nigeria, the Labour Act (2004) is responsible for protecting working mothers and their needs at the workplace to enable them to thrive while the National Policy on Infant and Young Child Feeding (2010) provides guidelines for feeding children aged 0-5 years. However, it appears that both policies do not fully account for the need of the breastfed child and nursing mothers within the workplace. Thus, undermining the child's right to breast milk and the working mother's decision to breastfeed.

Maternity leave: According to the WHO, a child should be fed breast milk only from o-6 months of age (WHO, 2011). Although, the National Policy on Infant and Young Child Feeding in Nigeria (2010) supports this recommendation (FMoH, 2010, p. vi), the Labour Act (2004) in section 54(1) does not afford working mothers the full support to abide by the recommendation. The later grants 3 months maternity leave to employed mothers which cover half of the EBF duration. Surprisingly, this leave is less than the 14 weeks recommended by the ILO (Aikawa, et al., 2015), and even lesser when compared to countries like the UK where working mothers are allowed to take up to 12 months maternity leave (GOV.UK, 2020). Therefore, by law working mothers in Nigeria must return to work after 3 months of delivery. Also, section 54(1) of the Labour Act (2004) permits a working mother to take the leave 6 weeks before delivery on medical grounds leaving such a mother with only 6 weeks to practice EBF in the comfort of home.

From these pieces of evidence, it appears that this directive aims at providing a few weeks post-partum rest for the working mothers rather than promoting EBF practice among the working mothers. Nigeria's maternity leave is short when compared to the WHO's 6 months recommendation for EBF. Therefore, this affects the mother's commitment to practice EBF which is demanding (Osibogun, et al., 2018).

Maternity pay: Aside from the maternity leave being short, subsection 54(1)(c) states that only mothers who have been employed for 6 months or more are entitled to at least $50 \%$ of their pay. A condition that invariably marginalizes newly employed mothers delivered of a child in less than 6 months of employment. This undermines the working mothers' ability to financially support her family particularly the infant. Although the evidence did not acknowledge finance as a barrier to EBF among working mothers, it is evident that in a bid to urgently return to work and get paid, working mothers in Nigeria may be deterred from practising EBF (Tsai, 2013). This is because these mothers are not only working to bridge the gender equality gap, they also do so to support their families financially (Fapohunda, 2012).

This directive potentially aims to protect employers and minimize the rate at which working mothers may take undue advantage of them and the law (Worugji \& Etuk, 2005). Nonetheless, it negatively affects a working mother's decision to exclusively breastfeed. Despite these, there are still some state governments in Nigeria that understand the importance of adequate maternity leave and pay in EBF promotion. For example, Lagos, Kaduna and Enugu state grants female public workers within their states 6 months maternity leave with full pay (Alive \& Thrive, 2019).

Breastfeeding breaks: Subsection 54(1)(d) of the Labour Act (2004) states that working mothers in Nigeria are entitled to two breaks of half an hour each daily upon resumption to nurse her child. This is an effort to encourage working mothers to continue EBF upon resumption after 6-12 weeks of maternity leave depending on the individual case. However, this break is insufficient to meet the need for an exclusively breastfed child. This is because an infant is expected to be breastfed on demand (UNICEF, 2018) which is about 8-12 times daily during the first few months (CDC, 2018). Therefore, for every 12 hours, the baby breastfeeds at least 4 times - a commitment that is unachievable by a working mother with two breaks of half an hour each during working hours. 
Nature of work: In section 55(1), the Labour Act (2004) prohibits women in any establishment from night work. However, in section 55(2) nurses, women in private organizations, managerial positions, or in any agricultural establishment whose work do not require manual labour are allowed to work at night. Despite the attempt to protect women, certain categories of women (such as nurses) are not exempted from night work even on the grounds of nursing a child. It is problematic that even the frontline workers saddled with the obligation of promoting IYCF do not have the opportunity to practice it themselves. Arguably, this is attributable to the scarcity of nurses in Nigeria (Uchendu, et al., 2020). Currently, Nigeria is ranked the sixth country with the lowest number of nurses and doctors with a ratio of 23 nurses per 10,000 (Uchendu, et al., 2020). Effectively, certain categories of female workers are not protected by the law even during maternity leave thus deterring them from practising EBF.

Type of maternal work: Additionally, women are prohibited from a certain type of work such as underground work as stated in section 56(1) of the Labour Act (2004) with the exemption of those in managerial positions or those having underground work as a partial fulfilment of their study. Therefore, nursing mothers who are managers or who are undergoing a study in underground work are not exempted from work regardless of whether they are nursing a child. In this context, underground work refers to work done below the earth such as mining. With Nigeria's heavy reliance on crude oil which involves underground work (Aigbedion \& lyayi, 2007), there are still a few women within the sector engaged in underground work (IIED, 2018). This may have informed the government decision to ensure that those in managerial positions or studying for a career in such field be allowed to work.

The Nigerian government does not recognize that every USD 1 invested in breastfeeding yield USD 35 (Global Breastfeeding Investment Case, 2017), such that the Labour Act (2004) does not account for the additional challenges certain types of work may pose on nursing mothers within the workforce. Therefore, it can be argued that the Labour Act (2004) does not account for the barrier to EBF arising from the nature and type of work of working mothers.

Interestingly, while the Labour Act (2004) makes ambitious efforts to address structural work-related factors, the National Policy on Infant and Young Child Feeding in Nigeria (2010) only accounts for working mothers in its specific objective (FMoH, 2010, p. 19). Presumably, this is attributable to Nigeria's gender norm which expects women to be sit-at-home mothers rather than career women who work outside their homes (Lodin, et al., 2019). Also, the policy may have been formulated based on the thriving perception that fewer women are working as opposed to the actual statistic revealed by the Institute, Evidence and Learning for Development (2019).

Breastfeeding space and facilities: Despite the limited acknowledgement of working mothers in the National Policy on Infant and Young Child Feeding in Nigeria (2010), the policy advocates for the provision of an enabling environment which promotes breastfeeding space within the workplace $(\mathrm{FMoH}, 2010, \mathrm{p}$. 4). However, working mothers in Nigeria lack breastfeeding space at their workplace (Okwy-Nweke et al., 2014) attributable to the lack of penalty for defaulters - that is the employers (ILO, 2012). Hence, like mothers in Pakistan, working mothers in Nigeria have to travel a considerably long distance to the crèche to nurse the infant (Zafar \& Bustamante-Gavino, 2008). This is challenging because breastfeeding breaks granted by the Labour Act (2004) in subsection 54(1)(d) is short and does not take into consideration the distance travelled by the mother to nurse her child at home or crèche. Presumably, this informed the promotion of breastfeeding support groups to encourage mothers especially those working to continue EBF amidst challenges (FMoH, 2010, p. 19). Similarly, the Labour Act (2004) promotes maternity leave and breastfeeding breaks and exemption of women in a certain type of work - however, in a manner that is insufficient to promote and improve EBF among working mothers in Nigeria.

Like Malaysia, working mothers in Nigeria lack breastfeeding facilities such as refrigerators useful in preserving expressed breastmilk for future use (Amin et al., 2011). The expressed breastmilk - which refers to breast milk squeezed out of a mother's breast to be fed to a child - typically lasts 4 hours at room temperature and 4 days in a refrigerator and can even last up to 6 months in a freezer of $-18^{\circ} \mathrm{C}$ (CDC, 2019). Invariably, this highlights the importance of such facilities in encouraging mothers to exclusively breastfeed. Despite this, only the National Policy on Infant and Child Feeding addresses this by encouraging an enabling environment for working mothers (FMoH, 2010, p. 4).

Attitudinal factors: Aside from the poor workplace structure, poor attitudes of co-workers and employers towards working mothers deter them from exclusively breastfeeding upon resumption of work. Although the National Policy on Infant and Young Child Feeding in Nigeria is not directly targeted at co-workers and 
employers, it makes an ambitious attempt to discourage discrimination among working mothers ( $\mathrm{FMoH}$, 2010, p. 19). Similarly, section 46(1) of the Labour Act (2004) prohibits employers from ill-treating their employees. Although not explicitly stated by the Labour Act (2004), this ill-treatment may likely include maternity leave refusal (if entitled to it) and criticism during breastfeeding.

Both directives address the structural work-related barriers that deter working mothers from exclusively breastfeeding to a considerable extent given the economic capacity in Nigeria. However, they both lack the compliance mechanism to ensure strict adherence to these directives. For instance, the National Policy on Infant and Young Child Feeding in Nigeria (2010) promotes enabling environment void of discrimination $(\mathrm{FMoH}, 2 \mathrm{O} 0, \mathrm{p} .4)$, but fails to state the penalty accrued to defaulters of such directive. Conversely, the Labour Act promotes maternity leave and breastfeeding breaks, exempts women in a certain type of work and discourages the ill-treatment of workers including working mothers - and states in section 46(1) that defaulters are liable to a fine of less than NGN 500 or less than a year imprisonment or both. However, this penalty is minimal to compel compliance with the law (Worugji \& Etuk, 2005).

The minimal penalty encourages poor attitude among employers which in turn results in attitudinal barriers to EBF for the working mothers. Subsequently, this encourages employees (particularly working mothers) to forfeit the available workplace structure to secure their jobs. Furthermore, while the law is aimed at protecting the working mother's maternity right, subsection 54(2)(b) of the Labour Act (2004) under no circumstance guarantees job security to a working mother on maternity leave if she exceeds the leave. Hence, these women are forced to choose their work over their welfare and that of their breastfed infant due to the high level of unemployment and economic hardship facing Nigeria (Adelowokan et al., 2019).

\subsection{Maternal factors}

Aside from work and social factors, maternal factors are factors that deter working mothers in Nigeria from exclusively breastfeeding. This includes poor lactation, birth by caesarean section, poor health conditions, perceptions and emotions of mothers.

Poor lactation: Although poor lactation has been attributed to work stress (Okwy-Nweke et al., 2014), the Labour Act (2004) neither makes provision for workload reduction for working mothers nor encourages flexible working hours for them. Also, concerning certain types of works involving manual labour done by women such as underground work as stated in section 56(1) which may affect lactation (Okwy-Nweke et al., 2014), working mothers were not acknowledged. Similarly, infants of poor lactating mothers were not considered in the National Policy on Infant and Young Child Feeding in Nigeria (2010) - despite the policy's acknowledgement of infants of HIV-positive mothers (FMoH, 2010, p. vi) and the involvement of the Nutrition Society of Nigeria (NSN) in its formulation (FMoH, 2010, p. iii). Arguably, the omission may be attributable to the poor engagement of necessary stakeholders like nutritionists and dieticians, for example, the formulation of the National Policy on Infant and Young Child Feeding in Nigeria (2010) was led by a medical practitioner (Afikpo Online, 2013). However, like the National Food and Nutrition Policy (NFNP) formulation, it may have been increasingly difficult to engage nutritionist during the National Policy on Infant and Young Child Feeding in Nigeria (2010) formulation due to the nutrition emergency caused by the Boko Haram insurgency in North-East, Nigeria which began since 2002 (Nutrition Exchange, 2018).

Birth by caesarean section: Similarly, the National Policy on Infant and Young Child Feeding in Nigeria (2010) does not account for infants delivered through caesarean section despite accounting for other infants with special needs (FMoH, 2010, pp. 9-18). This is problematic considering the implications and high rate of caesarean section in Nigeria (Ugwu, et al., 2011). It further indicates the little or no consideration given to the maternal factors by the Nigerian government.

Maternal health: Regarding poor maternal health, no specific health condition was revealed by the evidence. However, a quantitative study conducted among Chief Resident Doctors in Nigeria, $55.2 \%$ admitted that a mother's HIV status was a major contraindication to EBF followed by mastitis, breast cancer, tuberculosis and drug use such as cytotoxic drugs (Agbo, et al., 2013). It is possible that working mothers that reported poor health condition as a barrier in the included studies may have been HIV-positive but were unable to disclose it for fear of stigmatization (Odimegwu, et al., 2017). The National Policy on Infant and Young Child Feeding in Nigeria addresses this barrier extensively such that it was revised in 2010 - to encourage EBF among HIV-positive mothers ( $F M o H, 2010, p$. vi). This may be attributed to the fact that the policy revision was led by the former Honourable Minister of Health, Professor C. O. Onyebuchi who is a medical practitioner and has served in such capacity throughout his career (Afikpo Online, 2013). The 
directive also respects mothers' decision to do otherwise as a way of protecting their human right (FMoH, 2010, p. vi). Hence, a majority of working mothers in Nigeria opt for formula feeding for fear of motherto-child transmission of HIV (Agbo, et al., 2013), like most mothers in South Africa (Ogbo, et al., 2017). Unfortunately, the directive does not consider other forms of poor health conditions revealed by Agbo, et al (2013). Also, section 54(1) of the Labour Act (2004) only considers a working mother's health within 6 weeks pre-natal following a medical report.

Perceptions and emotions: Working mothers perceived breast milk as insufficient and infant formula as more beneficial (Tadesse et al., 2019). This was addressed indirectly in the National Policy on Infant and Young Child Feeding in Nigeria (2010) by promoting counselling, training and support towards achieving IYCF (FMoH, 2010, p. 20). Although, the policy encourages that distribution of breast milk substitutes in Nigeria be regulated (FMoH, 2010, p. 20) in compliance with the Marketing Act (1990) which prohibits the advertisement of infant formula (Access to Nutrition Index, 2018, p. 6). However, Nigeria's infant food formula market has grown consistently and was estimated at NGN 114. 9 billion in 2017 due to poor policy implementation (Access to Nutrition Index, 2018, p. 7).

Also, psychological stress such as emotional trauma affects these mothers (Valizadeh et al., 2017) resulting in shyness and guilt during breastfeeding (Hirani \& Karmaliani., 2013). Commendably, both policies discourage ill-treatment and discrimination which deter working mothers from exclusively breastfeeding (FMoH, 2O10, p. 4; ILO 2012).

\subsection{Social factors}

Evidence reveals that poor family support (especially from the spouse and mother-in-law) and poor societal support from health workers, day-care facilities and religious groups can deter working mothers from practising EBF (Gebrekidan et al., 2020)

Family factors: Aside from the mother, the father assumes the role of the second proximal family member to an infant. Like Indian men, Nigerian men are unlikely to support their wives in childcare especially during the period of maternity leave (Chhetri, et al, 2018). This attitude which may be attributed to the demanding nature of the fathers' occupation and their poor EBF knowledge (Chhetri, et al, 2018) undermines the essence of the maternity leave. The Labour Act (2004) aimed at protecting the Nigerian workforce makes no provision for paternity leave to enable fathers to support their nursing wives during childcare. As a result, only two Nigerian states (Lagos and Enugu states) offers paternity leave (of 2 and 3 weeks respectively) (Global Legal Group, 2020).

Also, poor EBF knowledge by the father (Chhetri, et al., 2018) and mother-in-law (Okwy-Nweke et al., 2014) deter them from supporting the working mothers to exclusively breastfeed. Although the National Policy on Infant and Young Child Feeding in Nigeria (2010) addresses this by promoting counselling and support services, capacity building and development, and advocacy and social mobilization, (FMoH, 2010, pp. 20), it offers no strategy to ensure that fathers and mothers-in-law are sensitized on the importance of EBF.

Societal factors: Beyond family and work, working mothers interact with the larger society which includes hospitals, religious settings and public spaces. Like in Ethiopia, poor EBF knowledge of members of the larger society negatively influences a mother's decision to EBF in Nigeria (Taddele et al., 2014). The National Policy on Infant and Young Child Feeding in Nigeria refers to these individuals (which includes health workers, religious leaders and crèches owners) as caregivers (FMoH, 2010, p. i-ii). Through the promotion of advocacy, social mobilization, counselling, support services, capacity building and development, research, monitoring and evaluation, supervision, coordination, and $\mathrm{CBSC}(\mathrm{FMoH}, 2010, \mathrm{p} .20)$, the government ensures that these caregivers are well-informed to support working mothers. For example, it promotes both formal and informal IYCF training among health workers (FMoH, 2010, pp. 23-24).

Like in Pakistan, health workers are Nigeria's major sources of IYCF information among working mothers (Sabin et al., 2017). Research has shown that supports from health workers contributes to the early initiation of breastfeeding and longer duration of EBF among working mothers (Olaolorun \& Lawoyin, 2006). However, many of these health workers are ill-prepared for such role due to poor pre-service training which does not equip them with the much-needed skill to support working mothers (Olaolorun \& Lawoyin, 2006). Furthermore, due to the low health workers-to-patients ratio in Nigeria (Uchendu, et al., 2020), health workers either fail to acknowledge the impact of inaccurate information or are reluctant to allocate adequate time to support breastfeeding mothers (Olaolorun \& Lawoyin, 2006). 
Additionally, the National Policy on Infant and Young Child Feeding in Nigeria (2010) emphasizes IYCF research to promote up-to-date and evidence-based healthcare service delivery (FMoH, 2010, p. 24). However, these researches are largely focused on breastfeeding benefits and practice which is known rather than breastfeeding support at primary care centres (Olaolorun \& Lawoyin, 2006) - attributable to the lack of specific appointee to lead such research. In addition to this limiting factor, the directive provides no penalty for defaulters which may be attributed to the poor mechanism in place to achieve the directives.

\section{Conclusion}

From the evidence, work-related factors were considered the major barrier to EBF among working mothers, followed by maternal and social factors. Concerning the work-related factors, maternity leave and breaks were partially addressed such that they remain insufficient to improve EBF among working mothers in Nigeria. However, breastfeeding spaces were encouraged while poor workplace attitudes that deter EBF practice were discouraged by both policies. Unfortunately, the Nigerian policy did not consider the nature and type of maternal work for working mothers. Concerning the maternal factors, the directives did not consider poor lactation and birth by caesarean section. Only HIV was considered as a maternal health condition that may deter EBF among working mothers. Although ill-treatment and discrimination were addressed, issues of perception were only addressed indirectly - which questions the clarity of the policy to the public. Commendably, when it comes to social factors activities such as sensitization, advocacy, capacity building and research were extensively addressed. However, no provision was made for paternity leave.

Nigeria is striving to improve EBF among working mothers but there are huge policy gaps, lack of policy coherence and disparities between the policy and its implementation. These were attributed to lack of clearly defined policy, an insufficient mechanism to spur compliance (such as lack or minimal penalty), inadequate human capital (for example health workers shortage), and redundant research. This results in demotivation of citizens (such that employers deny working mothers of their maternity leave), capital wastage (such as prioritization of research on EBF benefits over EBF support) and subsequently underdevelopment. Hence, more effort is needed to improve the EBF rate among working mothers as there is no coherence between both policies.

This task solely relies on the Nigerian government. The government should not only ensure that policies are evidence-based, but policies must also be constantly reviewed and adequately funded. Relevant stakeholders such as nutritionists and dieticians should be engaged during the formulation of nutritionspecific policies and maternity leave in Nigeria should be increased to six months to enable working mothers' practice EBF. Also, proper structural and machinery measures must be put in place to ensure that citizens adhere to the policies - to compel employers to provide maternity leaves, breaking breaks and breastfeeding spaces to working mothers. The Nigerian government should also offer training and incentives to health workers and individuals pursuing careers in early childhood development respectively to enable them to provide the much-needed support to all mothers especially the working mothers.

Working mothers should only comply with national directives on IYCF and learn to debunk myths associated with EBF. Most importantly, they should prioritise their well-being for their sake and that of the breastfed child. Also, members of the family and public should support working mothers at all times especially during the first 6 months of their delivery when breastfeeding can be highly demanding.

While this paper has identified the barriers to EBF among working mothers in Nigeria and the extent to which these barriers are addressed by the Nigerian policy, it has also recommended the roles governments and stakeholders can play to improve EBF in Nigeria. However, further research is encouraged to monitor the impact of these recommendations.

\section{References}

Access to Nutrition Index. (2018). Marketing of Breast-milk Substitutes. Access to Nutrition Index.

Adelowokan, O. A., Babasanya, A. O., Maku, O. E. \& Adesoye, A. B., (2019). Unemployment, Poverty and Economic Growth in Nigeria. Journal of Economics and Management, 35(1). 6-17 . http://doi.org/10.22367/jem.2019.35.01

Afikpo Online, (2013). Prof. Onyebuchi Chukwu (Profile). Discover Afifkpo. https://www.afikpoonline.com/prof-onyebuchi-chukwu-profile/ 
Agbo, H. A., Envuladu, E. A., Adams, H. S., Inalegwu, E., Okoh E., Agba, A. \& Zoakah, A. I. (2013). Barriers and Facilitators to The Practice of Exclusive Breast feeding Among Working Class Mothers: A Study of Female Resident Doctors in Tertiary Health Institutions in Plateau State. E3 Journal of Medical Research, 2(1). 0112-0116. https://www. e3journals.org/cms/articles/1365364023_EJMR-13-012-GALLEY\%2OPROOF.pdf

Aigbedion, I. \& Iyayi, S. E. (2007). Diversifying Nigeria's Petroleum Industry. International Journal of Physical Sciences, 2(10). 263-270. https://doi.org/10.5897/IJPS.9000178

Aikawa, T., Pavadhgul, P., Chongsuwat, R., Sawasdivorn, S. \& Boonshuyar, C. (2015). Maternal Return to Paid Work and Breastfeeding Practices in Bangkok, Thailand. Asia Pacific Journal of Public Health, 27(2). 1253-1262. https://doi. org/10.1177/1010539511419647

Akinyemi, J. O., Solanke, B. L. \& Odimegwu, C. O. (2018). Maternal Employment and Child Survival During the Era of Sustainable Development Goals: Insights from Proportional Hazards Modelling of Nigeria Birth History Data. Annals of Global Health, 84(1). 15-30. http://doi.org/10.29024/aogh.11

Alive \& Thrive. (2019). Maternity Entitlements in Nigeria: Policies and practices. Family Health Department of The Federal Ministry of Health, Alive \& Thrive and UNICEF.

Amin, R. M., Said Z. M., Sutan R., Shah S. A., Darus A. \& Shamsuddin K. (2011). Work Related Determinants of Breastfeeding Discontinuation Among Employed Mothers in Malaysia. International Breastfeeding Journal volume, 6(4). https://doi.org/10.1186/1746-4358-6-4

CDC. (2018). How Much and How Often to Breastfeed. Centers for Disease Control and Prevention. https://cutt.ly/3nkZ1eZ

CDC. (2019). Storage and Preparation of Breastmilk. Centers for Disease Control and Prevention https://cutt.ly/9nkX2ji

Chekol, D. A., Biks, G. A., Gelaw, Y. A. \& Melsew, Y. A. (2017). Exclusive Breastfeeding and Mothers' Employment Status in Gondar Town, Northwest Ethiopia: A Comparative Cross-Sectional Study. International Breastfeeding Journal, 12(1). https://doi.org/10.1186/s13006-017-0118-9

Chhetri, S., Rao, A. P. \& Guddattub, V. (2018). Factors Affecting Exclusive Breastfeeding (EBF) Among Working Mothers in Udupi Taluk, Karnataka. Clinical Epidemiology and Global Health, 6(4). 216-219. https://doi.org/10.1016/j. cegh.2018.06.008

Fapohunda, T. M., (2012). Gender and Development: Challenges to Women Involvement in Nigeria's Development. International Journal of Academic Research in Business and Social Sciences, 2(6). 14-28. https://cutt.ly/ynkCb1l

FMoH, (2010). Federal Ministry of Health. https://www.health.gov.ng/doc/IYCFPolicy.pdf

Gebrekidan, K., Fooladi, E., Plummer, V. \& Hall, H., (2020). Enablers and Barriers of Exclusive Breastfeeding Among Employed Women in Low and Lower Middle-Income Countries. Sexual and Reproductive Healthcare, 25:100514. https://doi.org/10.1016/j.srhc.2020.100514

Global Breastfeeding Investment Case. (2017). Nurturing the Health and Wealth of Nations: The Investment Case for Breastfeeding. World Health Organization.

Global Legal Group. (2020). Employment and Labour Law 2020. International Comparative Legal Guides.

GOV.UK. (2020). Maternity Leave and Pay. GOV.UK https://www.gov.uk/maternity-pay-leave/leave

Hirani, S. A. A. \& Karmaliani, R. (2013). The Experiences of Urban, Professional Women When Combining Breastfeeding with Paid Employment in Karachi, Pakistan: A Qualitative Study. Women and Birth, 26(2). 147-151. https://doi. org/10.1016/j.wombi.2012.10.007

IBFAN. (2017). Report on The Situation of Maternal Health and Work-related Issues in Nigeria. International Baby Food Action Network.

IIED. (2018). Women in Artisanal and Small-Scale Mining: Challenges And opportunities for greater participation. International Institute for Environment and Development.

ILO. (2012). International Labour Organization. [Online] Available at: https://cutt.ly/anWr5ND [Accessed 02 July 2020].

Institute, Evidence and Learning for Development, (2019). Gender Roles and Inequalities in the Nigeria Labour Market. Institute, Evidence and Learning for Development.

Krippendorff, K. (2004). Content Analysis: An Introduction to Its Methodology. Sage Publications.

Lodin, J. B., Tegbaru, A., Bullock, R., Degrande, A., Nkengla, L. W. \& Gaya, H. I. (2019). Gendered Mobilities and Immobilities: Women's and Men's Capacities for Agricultural Innovation in Kenya and Nigeria. Gender, Place and Culture, 26(12). 1759-1783. https://doi.org/10.1080/0966369X.2019.1618794

Midgley, J. \& Livermore, M. (2009). Introduction: Social Policy and Social Welfare. In: J. Midgley \& M. Livermore. Handbook of Social Policy. SAGE.

NBS \& UNICEF, (2018). Multiple Indicator Cluster Survey 2016-17 (MICS), Abuja: National Bureau of Statistics (NBS) and United Nations Children's Fund (UNICEF). https://www.unicef.org/nigeria/reports/multiple-indicator-cluster-survey-2016-17-mics 
Nkrumah, J., (2016). Maternal Work and Exclusive Breastfeeding Practice: A Community Based Cross-Sectional Study in Efutu Municipal, Ghana. International Journal of Breastfeeding, 12(1). https://doi.org/10.1186/s13006-017-0100-6

Nutrition Exchange. (2018). Shaping National Food and Nutrition Policy in Nigeria. https://www.ennonline.net/shapingnationalfoodandnutritionpolicyinnigeria

Obamwonyi, S. E. \& Aibieyi, S. (2014). Public Policy Failures in Nigeria: Pathway to Underdevelopment. Public Policy and Administration Research, 4(9). 38-43. https://www.iiste.org/Journals/index.php/PPAR/article/view/15671

Odimegwu, C. O., Akinyemi, J. O., \& Alabi, O. O. (2017). HIV-Stigma in Nigeria: Review of Research Studies, Policies, and Programmes. AIDS Research and Treatment, 1-13. https://doi.org/10.1155/2017/5812650

Ogbo, F. A., Agho, K. E. \& Page, A., (2015). Determinants of Suboptimal Breastfeeding Practices in Nigeria: Evidence from the 2008 Demographic and Health Survey. BMC Public Health, 15(259). https://doi.org/10.1186/s12889-0151595-7

Ogbo, F. A., Page A., Idoko J., Claudio F., \& Agho K. E. (2017). Have Policy Responses in Nigeria Resulted in Improvements in Infant and Young Child Feeding Practices in Nigeria?. International Breastfeeding Journal, 12(9). https:// doi.org/10.1186/s13006-017-0101-5

Okwy-Nweke, C. P., Anyanwu, J. O. \& Maduforo, A. N. (2014). Mothers Beliefs and Obstacles as Limitations in Promoting Exclusive Breastfeeding Among Working-Class Mothers Attending Infant Welfare Clinic at University of Nigeria Teaching Hospital (UNTH), Enugu State. Clinical Medicine Research, 3(4). 105-111. https://doi.org/10.11648/j. cmr.20140304.15

Olaolorun, F., \& Lawoyin, T. (2006). Health Workers' Support for Breastfeeding in Ibadan, Nigeria. Journal of Human Lactation, 22(2). 188-194. https://doi.org/10.1177/0890334406287148

Osibogun, O. O., Olufunlayo, T. F. \& Oyibo, S. O. (2018). Knowledge, attitude and support for exclusive breastfeeding among bankers in Mainland Local Government in Lagos State, Nigeria. International Breastfeeding Journal, 13(38). 1-7. https://doi.org/10.1186/s13006-018-0182-9

Sabin, A., Manzur, F., \& Adil, S., (2017). Exclusive Breastfeeding Practices in Working Women of Pakistan: A Cross-Sectional Study. Pakistan Journal of Medical Science, 33(5). 1148-1155. https://doi.org/10.12669/pjms.335.12827

Taddele, M., Abebe, L. \& Fentahun, N. (2014). Exclusive Breastfeeding and Maternal Employment in Ethiopia: A Comparative Cross-Sectional Study. International Journal of Nutrition and Food Sciences, 3(6). 497-503. https://doi. org/10.11648/j.ijnfs.20140306.12

Tadesse, F., Alemayehu Y., Shine S., Asresaghegn, H., \& Tadesse, T. (2019). Exclusive Breastfeeding and Maternal Employment Among Mothers of Infants from Three to Five Months Old in the Fafan Zone, Somali Regional State of Ethiopia: A Comparative Cross-Sectional Study. BMC Public Health, 19. 1015. https://doi.org/10.1186/s12889$019-7345-5$

Tsai, S. (2013). Impact of a Breastfeeding-Friendly Workplace on an Employed Mother's Intention to Continue Breastfeeding After Returning to Work. Breastfeeding Medicine, 8(2). 210-216. https://doi.org/10.1089/bfm.2012.0119

Uchendu, C., Windle, R., \& Blake, H. (2020). Perceived Facilitators and Barriers to Nigerian Nurses' Engagement in Health Promoting Behaviours: A Socio-Ecological Model Approach. International Journal of Environmental Research and Public Health, Volume 17. 1-20. https://doi.org/10.3390/ijerph17041314

Ugwu, E., Obioha, K., Okezie, O., \& Ugwu, A. (2011). A Five-year Survey of Caesarean Delivery at a Nigerian Tertiary Hospital. Annals of Medical and Health Sciences Research, 1(1). 73-83. https://pubmed.ncbi.nlm.nih.gov/23209958/

United Nations, (2018). World Economic Situation and Prospects 2018 163/207. United Nations https://cutt.ly/QnkVNxK

Valizadeh, S., Hosseinzadeh M., Mohammadi E., Hassankhani H., Fooladi M \& V. Schmied. (2017). Addressing Barriers to Health: Experiences of Breastfeeding Mothers After Returning to Work. Nursing and Health Sciences, 19. 105111. https://doi.org/10.1111/nhs.12324

WHO, (2011) Exclusive Breastfeeding for Six Months Best for Babies Everywhere. WHO. https://cutt.ly/VnkBrQF

Worugji, I. N. E. \& Etuk, S. J., (2005). The National Breastfeeding Policy in Nigeria: The Working Mother and the Law. Health Care for Women International, 26(7). 534-554. https://doi.org/10.1080/07399330591004863

Zafar, N. S. \& Bustamante-Gavino, I. M., (2008). Breastfeeding and Working Full-time Experiences of nurse mothers in Karachi, Pakistan. International Journal of Caring Sciences, 1(3). 132-139.

AUTHOR

Linda Nwaodu. Bachelor's degree in Human Nutrition and Dietetics from the University of Ibadan, Nigeria and a Master's Master's degree in Global Health Policy from the University of Edinburgh, UK. Her research interests include; Health P. Health Policy, Maternal and Child Health and Public Health.

Conflict of interest

No potential conflict of interest is reported by the author. Funding

No financial assistance from parties outside this article. Acknowledgments 